\title{
Factors that lessen the burden of treatment in complex patients with chronic conditions: a qualitative study
}

\author{
Jennifer L Ridgeway ${ }^{1,2}$ \\ Jason S Egginton ${ }^{1,2}$ \\ Kristina Tiedje ${ }^{3}$ \\ Mark Linzer ${ }^{4,5}$ \\ Deborah Boehm ${ }^{4}$ \\ Sara Poplau ${ }^{6}$ \\ Djenane Ramalho de \\ Oliveira $^{7}$ \\ Laura Odell ${ }^{8}$ \\ Victor M Montori ${ }^{2,9}$ \\ David T Eton ${ }^{1,2}$
}

'The Mayo Clinic Robert D. and Patricia E. Kern Center for the Science of Health Care Delivery, ${ }^{2}$ Division of Health Care Policy and Research, Department of Health Sciences Research, Mayo Clinic, Rochester, MN, USA; ${ }^{3}$ Department of Anthropology, Université Lumière Lyon 2, Lyon, France; ${ }^{4}$ Division of General Internal Medicine, Hennepin County Medical Center, ${ }^{5}$ University of Minnesota Medical School, ${ }^{6}$ Minneapolis Medical Research Foundation, Minneapolis, MN, USA; ${ }^{7}$ Department of Social Pharmacy, Universidade Federal de Minas Gerais, Brazil; ${ }^{8}$ Pharmacy Services, ${ }^{9}$ Knowledge and Evaluation Research Unit, Mayo Clinic, Rochester, MN, USA

Correspondence: David T Eton

Division of Health Care Policy and

Research, Department of Health Sciences

Research, Mayo Clinic, 200 First Street

SW, Rochester, MN 55905, USA

Tel + I 507293 I353

Fax +| 507284 |73|

Email eton.david@mayo.edu
This article was published in the following Dove Press journal:

Patient Preference and Adherence

19 March 2014

Number of times this article has been viewed

\begin{abstract}
Purpose: Patients with multiple chronic conditions (multimorbidity) often require ongoing treatment and complex self-care. This workload and its impact on patient functioning and wellbeing are, together, known as treatment burden. This study reports on factors that patients with multimorbidity draw on to lessen perceptions of treatment burden.
\end{abstract}

Patients and methods: Interviews $(n=50)$ and focus groups $(n=4$ groups, five to eight participants per group) were conducted with patients receiving care in a large academic medical center or an urban safety-net hospital. Interview data were analyzed using qualitative framework analysis methods, and themes and subthemes were used to identify factors that mitigate burden. Focus groups were held to confirm these findings and clarify any new issues. This study was part of a larger program to develop a patient-reported measure of treatment burden.

Results: Five major themes emerged from the interview data. These included: 1) problemfocused strategies, like routinizing self-care, enlisting support of others, planning for the future, and using technology; 2) emotion-focused coping strategies, like maintaining a positive attitude, focusing on other life priorities, and spirituality/faith; 3) questioning the notion of treatment burden as a function of adapting to self-care and comparing oneself to others; 4) social support (informational, tangible, and emotional assistance); and 5) positive aspects of health care, like coordination of care and beneficial relationships with providers. Additional subthemes arising from focus groups included preserving autonomy/independence and being proactive with providers.

Conclusion: Patients attempt to lessen the experience of treatment burden using a variety of personal, social, and health care resources. Assessing these factors in tandem with patient perceptions of treatment burden can provide a more complete picture of how patients fit complex self-care into their daily lives.

Keywords: adherence, patient-centered, minimally disruptive medicine, patient preferences

\section{Introduction}

Chronic illnesses require ongoing treatment and self-management. The combined workload of prescribed health care activity and its impact on patient functioning and well-being is known as treatment burden. ${ }^{1}$ Treatment burden is an important clinical concern as it can result in poorer adherence to prescribed treatments and self-care, ${ }^{2,3}$ which has been linked to worse clinical outcomes, such as more hospitalizations, ${ }^{4}$ higher mortality, ${ }^{4,5}$ and poorer health-related quality of life. ${ }^{6,7}$

Understanding treatment burden is also a high priority topic for health care reform. The recent emphasis on quality of care metrics, emanating from work by McGlynn et al showing that only $55 \%$ of patients receive the care that they need for chronic illness, has led to a proliferation of new techniques (eg, care coordination) for improving the 
management of chronic illness aspects, such as hemoglobin $\mathrm{A}_{1 \mathrm{c}}$, low-density lipoprotein (LDL) cholesterol, blood pressure, and the like. ${ }^{8}$ The need to control these parameters has markedly expanded the requests that providers and health systems make of patients in the interest of long-term improvement in morbidity or mortality.

However, while patients are expected to adapt to the expanding burdens of treatment and care, it is less clear that providers understand the depth of this burden, the impact it has on patients, and what can be done to help lessen it. Tools are needed to quantify treatment burden and the factors that may influence it so that providers and patients are able to engage in meaningful discussions about it, including ways of potentially reducing it. We recently modified a previously articulated conceptual framework of treatment burden, ${ }^{1}$ using data from semistructured interviews and focus groups (FGs) with patients with multiple chronic conditions. This framework will ultimately serve as a guide to develop a novel patient self-report measure of treatment burden, which providers will be able to use to assess the degree of burden facing a patient and to begin a dialogue about patient preferences.

In addition to conceptualizing treatment burden, our qualitative inquiry also uncovered several factors that, when present, might lessen perceived burden. While studies have investigated these mitigating factors in single diseases, ${ }^{9-11}$ less attention has been paid to them in patients dealing with multiple chronic conditions and complex self-management. In this article we use the term "multimorbidity" to refer to the presence of two or more chronic conditions. ${ }^{12}$ Related to this is the concept of comorbidity, which refers to health problems that exist or co-occur with a disease (eg, retinal disease in diabetes). ${ }^{13}$ For many patients, treatment demands increase in intensity as new conditions are diagnosed and management protocols add more medications, tests, and medical appointments to the self-care regimen. ${ }^{14-16}$ Demands are further amplified if these conditions require specialized care that involves seeing multiple providers ${ }^{12,17-19}$ or if patients and providers need to reconcile separate guidelines for care..$^{20}$ The consequences of this complexity may include conflicting treatments and disease management strategies, which can raise the risk of drug interactions and increase health care costs. ${ }^{20-22}$

For this report we summarize our interview and FG findings on the personal-, social-, and provider-level factors that patients with multimorbidity draw on to lessen treatment burden. Understanding attenuators of burden is critical since it is hypothesized that imbalance between the demands of self-care and an individual's capacity to cope with these demands can lead to higher perceived treatment burden and, ultimately, poor clinical outcomes, including nonadherence to treatment. ${ }^{23}$

\section{Methods}

\section{Participant recruitment and setting}

Data were collected at Mayo Clinic, Rochester, Minnesota and at Hennepin County Medical Center (HCMC), Minneapolis, Minnesota. Mayo Clinic is a multispecialty, integrated practice in southeast Minnesota. HCMC is Minnesota's largest safety-net hospital and ambulatory clinic system providing care for low-income, uninsured and vulnerable persons. Combined, these settings captured a wide range of patient experiences.

\section{Interviews}

We used a purposeful sampling strategy that targeted patients who could provide information-rich accounts of treatment and self-care demands. This included patients with multimorbidity (as previously defined) involved in a complex regimen of self-care. Complex self-care could include taking multiple medications, monitoring health status, and/or following diet and exercise plans recommended by a health care provider. Mayo Clinic patients were recruited from a pharmacist-led medication therapy management support program. HCMC patients were recruited through flyers posted in the waiting area of the primary care outpatient clinic. Interested patients met with a study coordinator who assessed eligibility.

\section{Focus groups}

FG participants were recruited through patient advisory groups and disease-specific treatment clinics. The Mayo Clinic patients were recruited from two patient advisory groups, one in diabetes and one in heart failure. The HCMC patients were recruited from heart failure and renal clinics. The Institutional Review Boards at Mayo Clinic and HCMC approved the research, and all participants provided written consent.

\section{Data collection}

\section{Interviews}

Three experienced interviewers (DTE, JSE, and JLR) conducted interviews in the clinics between January 2010 and January 2013. The semistructured interview guide focused on how patients cared for their conditions and the impact that care had on them, including their personal life, social situation, and work. We also asked patients what factors made management of their care easier or more difficult. The 
interview guide, originally listed in Eton et al, ${ }^{1}$ was revised as new issues warranting exploration emerged. Demographic information was collected at the end of each interview.

\section{Focus groups}

Following the interviews, an experienced facilitator (KT) led FGs at both Mayo Clinic and HCMC. DTE, JSE, and JLR were present to observe and assist, and all team members made notes about their observations. The FG topic guide was based on a conceptual framework derived from the interviews. Intentional probes were used to uncover any new issues. Participants were asked to describe the work of caring for their health, how they organized their day to manage their care, and factors that made care more and less difficult. The facilitator used probes to elicit feedback on themes and subthemes of the conceptual framework. Basic demographic information was collected by either chart review or direct patient query.

\section{Data analysis}

Analysis began with the interview data. All interviews were audio-recorded and transcribed verbatim. Two authors (DTE and DRdO) analyzed data from the Mayo Clinic interviews using framework analysis, a systematic procedure for identifying patterns within narrative data. ${ }^{24} \mathrm{~A}$ coding scheme (ie, "framework") was developed after independent review of the first five interviews, followed by discussion, and consensual agreement of the two analysts. The framework was then applied to subsequent transcripts and revised as needed when new themes and subthemes emerged. Hence, data collection and analysis occurred concurrently.

The data from the HCMC interviews were reviewed and coded independently by three members of the research team (DTE, JSE, and JLR), using the coding framework derived from the Mayo Clinic interviews. The team subsequently met and discussed each transcript, arriving at consensus on each passage of coded text. NVivo qualitative data analysis software (Version 10; QSR International Pty Ltd, Victoria, Australia) was used to facilitate data organization. When existing codes were insufficient, discussion ensued, and consensus was ultimately reached to either alter an existing code or add a new code. Once all interviews were coded, the team performed one last review and modified the conceptual framework accordingly.

Analysis of the FG data was tailored to the objectives of the groups, namely, to 1) confirm the framework arising from the interviews and 2) clarify any new (unrepresented) conceptual issues. These objectives lend themselves to a notesbased approach, whereby the data used included field notes and audio files. ${ }^{25}$ The facilitator (KT) and three members of the research team (DTE, JSE, and JLR) took detailed notes and held a debriefing session following each group to discuss findings. After the first two groups, top-line reports (preliminary reports produced quickly) were distributed to the clinical members of the study team (DB and ML) for feedback. ${ }^{25}$ Upon completion of all four FGs, two team members (DTE and JLR) compiled the data into a saturation grid outlining the themes that were identified in each group and refining any themes with overlapping or divergent content. KT and JSE reviewed the report and provided feedback. These data were used to finalize the conceptual framework of treatment burden (manuscript forthcoming). Themes representing potential resources for mitigating treatment burden form the basis of the present analysis. While our study was not designed to identify differences in the themes and subthemes between the two sites, in some instances our analysis did suggest a few potential differences. When observed, these differences are noted.

\section{Results}

\section{Patient characteristics}

A total of 50 patients were interviewed, 32 at Mayo Clinic and 18 at HCMC. The Mayo Clinic participants were slightly older than HCMC participants (mean $=59.5$ years $[\mathrm{YR}]$ vs $50.5 \mathrm{YR}$, respectively), more formally-educated (50\% college graduate vs $0 \%$ college graduate, respectively), and more likely to be married or living with a partner $(69 \%$ vs $22 \%$, respectively) (Table 1 ). More minorities were represented in the HCMC sample (89\%) than in the Mayo Clinic sample (3\%). The patients in both settings reported a median number of five health conditions requiring treatment or self-care.

Four FGs were held with a total of 25 patients (five to eight participants per group). The two Mayo Clinic groups featured patients from diabetes and heart failure patient advocacy groups ( $\mathrm{n}=12$; age range $52-87 \mathrm{YR}$; $42 \%$ female; and $0 \%$ nonwhite). The two HCMC groups featured patients from heart and renal failure clinics ( $n=13$; age range 47-70 YR; $46 \%$ female, and $69 \%$ nonwhite). The median number of self-reported health conditions was three (range: one to six) in the FGs.

\section{Interview results}

Five major themes emerged from the interview data, including problem-focused strategies, emotion-focused coping, questioning the notion of burden, receiving support from others, and positive aspects of health care. These represent resources, called 
Table I Characteristics of interviewees $(\mathrm{N}=50)$

\begin{tabular}{|c|c|c|}
\hline & $\begin{array}{l}\text { Mayo Clinic } \\
(n=32)\end{array}$ & $\begin{array}{l}\text { Hennepin County } \\
\text { Medical Center } \\
(n=18)\end{array}$ \\
\hline \multicolumn{3}{|l|}{ Age, years } \\
\hline Median & 59.5 & 50.5 \\
\hline Range & 26 to 85 & 25 to 61 \\
\hline \multicolumn{3}{|l|}{ Sex } \\
\hline Female & $20(63 \%)$ & $9(50 \%)$ \\
\hline Male & $12(38 \%)$ & $9(50 \%)$ \\
\hline \multicolumn{3}{|l|}{ Race } \\
\hline White & $3 \mid(97 \%)$ & $2(11 \%)$ \\
\hline African-American & I (3\%) & $13(72 \%)$ \\
\hline Native American & 0 & $2(11 \%)$ \\
\hline Mixed (African/ & 0 & I (6\%) \\
\hline \multicolumn{3}{|l|}{ Native American) } \\
\hline \multicolumn{3}{|l|}{ Education } \\
\hline $\begin{array}{l}\text { High school } \\
\text { graduate or less }\end{array}$ & $5(16 \%)$ & $12(67 \%)$ \\
\hline $\begin{array}{l}\text { Some college/ } \\
\text { technical degree }\end{array}$ & II (34\%) & $6(33 \%)$ \\
\hline College graduate & $16(50 \%)$ & 0 \\
\hline \multicolumn{3}{|l|}{ Marital status } \\
\hline $\begin{array}{l}\text { Married or living } \\
\text { with partner }\end{array}$ & $22(69 \%)$ & $4(22 \%)$ \\
\hline Not married & $10(31 \%)$ & 14 (78\%) \\
\hline \multicolumn{3}{|l|}{ Employment status } \\
\hline Retired/unemployed & $13(4 \mid \%)$ & $5(28 \%)$ \\
\hline Full-time employed & $10(31 \%)$ & $2(11 \%)$ \\
\hline Part-time employed & $4(13 \%)$ & $2(11 \%)$ \\
\hline On disability or leave & $4(13 \%)$ & $8(44 \%)$ \\
\hline Homemaker & I (3\%) & I (6\%) \\
\hline \multicolumn{3}{|c|}{ Self-reported health conditions } \\
\hline Median & 5 & 5 \\
\hline Range & I to 16 & 3 to 8 \\
\hline \multirow[t]{11}{*}{$\begin{array}{l}\text { Top ten most reported } \\
\text { health conditions }(n)\end{array}$} & $\begin{array}{l}\text { Gastrointestinal } \\
\text { problems (15) }\end{array}$ & Hypertension (14) \\
\hline & Hypertension (14) & $\begin{array}{l}\text { Depression or } \\
\text { anxiety (II) }\end{array}$ \\
\hline & $\begin{array}{l}\text { Arthritis/joint } \\
\text { pain (I3) }\end{array}$ & Arthritis/joint pain (8) \\
\hline & Diabetes (I2) & Back/neck problems (7) \\
\hline & $\begin{array}{l}\text { Cardiovascular } \\
\text { disease }(10)\end{array}$ & Diabetes (7) \\
\hline & Depression (I0) & Asthma/COPD (7) \\
\hline & Hyperlipidemia (8) & Obesity (6) \\
\hline & Back/neck & Drugs/alcohol/ \\
\hline & problems (8) & smoking (5) \\
\hline & Eye problems (8) & $\begin{array}{l}\text { Cardiovascular } \\
\text { disease (3) }\end{array}$ \\
\hline & $\begin{array}{l}\text { Sleeping } \\
\text { problems (7) }\end{array}$ & $\begin{array}{l}\text { Other mental health, } \\
\text { sleep disorders, chronic } \\
\text { pain, or migraine } \\
\text { headache (tied) (2) }\end{array}$ \\
\hline
\end{tabular}

Abbreviation: COPD, chronic obstructive pulmonary disease.

upon by the patient or supplied by others, that may ease the sense of burden patients ascribe to their health care work. These themes and their subthemes are summarized in Table 2 and described below, along with representative quotes. The patient's age (YR), race (African-American [AA]; white [W]; Native American
Table 2 Resources for easing treatment burden by data collection method

\begin{tabular}{|c|c|c|}
\hline Themes and subthemes & Interviews & Focus groups \\
\hline \multicolumn{3}{|l|}{ Theme I } \\
\hline Problem-focused strategies & $x$ & $x$ \\
\hline Routinizing self-care & $x$ & $x$ \\
\hline Enlisting support from others & $x$ & $x$ \\
\hline Planning for the future & $x$ & $x$ \\
\hline Using technology & $x$ & $x$ \\
\hline Preserving autonomy/independence & & $x$ \\
\hline Being proactive with providers & & $x$ \\
\hline \multicolumn{3}{|l|}{ Theme 2} \\
\hline Emotion-focused coping & $x$ & $x$ \\
\hline Maintaining positive attitude & $x$ & $x$ \\
\hline Focusing on other life priorities & $x$ & $x$ \\
\hline Spirituality and faith & $x$ & $x$ \\
\hline \multicolumn{3}{|l|}{ Theme 3} \\
\hline Questioning the notion of burden & $x$ & $x$ \\
\hline Adaptation/normalizing self-care & $x$ & $x$ \\
\hline Social comparison with others & $x$ & $x$ \\
\hline \multicolumn{3}{|l|}{ Theme 4} \\
\hline Receiving support from others & $x$ & $x$ \\
\hline Informational & $x$ & $x$ \\
\hline Instrumental & $x$ & $x$ \\
\hline Emotional/companionship & $x$ & $x$ \\
\hline \multicolumn{3}{|l|}{ Theme 5} \\
\hline Positive aspects of health care & $x$ & $x$ \\
\hline Systemic aspects & $x$ & $x$ \\
\hline Individual-provider aspects & $x$ & $x$ \\
\hline
\end{tabular}

Note: $\mathrm{x}$ indicates theme observed.

[NA]); and sex (male [M] and female [F]) are listed for each quote. Additional representative quotes from interviews and focus groups are included in the Supplementary material.

\section{Theme I: Problem-focused strategies}

Problem-focused strategies aim to directly alter, reduce, or eliminate the sources of treatment burden. For example, patients may use a pillbox or medication scheduler to facilitate medication management. Other problem-focused strategies mentioned by patients in interviews include routinizing self-care, enlisting the support of others, planning for the future, and using technology.

\section{Subtheme I: Routinizing self-care}

Patients reported embedding organizational tools and strategies into their daily routines to help with management of multiple or competing demands and reduce the chances of an important aspect of self-care being forgotten.

And so I have my alarm set to remind me to take that one [medication] [... ] because I'll forget. I'll get up and be like, okay, I gotta do this, this morning and I'll forget. Yeah, so I set an alarm so I'll always remember. [45 YR AAF] 


\section{Subtheme 2: Enlisting support from others}

Patients also described actively seeking support from others, either for tangible assistance or emotional support.

The last time the heart went bad. [...] I just walked into [my supervisor's] office and I said, "Hey, would you have one of the guys walk me to the bus." So he walked me to the shuttle bus; he rode with me to [the hospital], pushed me in a wheelchair to the emergency room. [63 YR WM]

I got one sister that I can call like in the middle of the night [...]. So sometimes, I have to ask - can I come over? Or can you come pick me up? Or can you just talk to me? [...] I'm feeling this way, I'm kind of depressed, or what should I do about this? [55 YR AAF]

\section{Subtheme 3: Planning for the future}

While present-day work was minimized by routinization, patients also spoke of strategies to address future needs, such as financial resources for health care in retirement and advance directives.

I do have a financial advisor and then I have been talking to friends that are either retired or nearing retirement to find out what they are going to do and just trying to get ideas. [60 YR WF]

I did one of these advance directives, but I put in there a provision that as long as I'm able to communicate, even if it is only by blinking my eyes, I am the one to decide when to terminate treatment. [82 YR WM]

This subtheme was noted in both interviews and FGs at Mayo Clinic but was less frequently observed at HCMC, with only one participant noting that she had thought about who might care for her in the future.

\section{Subtheme 4: Using technology}

Technology was vital for some patients. Online calendars, smart phone alarms, and other tools helped them get organized and provided reminders. Technology was also used to connect with health care providers, for example, using email or online portals.

When I get my labs checked, I look before my doctors do, I mean, because I look at them online like that day or whenever they come up. [26 YR WM]

I use "MyChart." If I need an appointment, I'll send the message. And I would request refills through "MyChart." [45 YR AAF]

And now they [health care providers] have this feature on the online service where you can send a note, so now
I use that $[\ldots]$ most of the time on the e-mail we can kind of get it figured out. [54 YR WF]

Online portals were the technology described most often in both settings, while smart phones and other electronic tools were more frequently reported by Mayo Clinic patients.

\section{Theme 2: Emotion-focused coping}

Emotion-focused coping strategies represent ways of managing the negative emotions associated with treatment burden and included maintaining a positive attitude, focusing on other life priorities, and spirituality and faith.

\section{Subtheme I: Maintaining a positive attitude}

Patients attempted to remain positive by exhibiting patience with others, positively reinterpreting the work of self-care, and using self-care success as motivation to persevere.

[...] trying not to let that erosion take away what you're about, because people can lose respect for you too if you're always like sickly. [60 YR WF]

Maybe they shouldn't find a cure for some stuff. I mean, I know that that sounds bad [...]. And the bad things in life, I think you have to go through that to really appreciate the good. [54 YR WF]

The success is taking it [the medication] as directed and seeing the results because it boosts your confidence to make you think, "Wow, I can do this!" [45 YR AAF]

\section{Subtheme 2: Focusing on other life priorities}

Some patients used distractions like hobbies and volunteer work as a means of "keeping spirits up" or taking their mind off their situation. As one patient described her sewing hobby:

It takes up time and it makes it so you got something else to think about besides yourself and being sick and stuff you don't want to think about. [53 YR AAF]

Another patient took solace in spending time outdoors:

The time that I'm happiest is when I'm in the woods by myself because I don't think about diabetes; I don't think about anything that is stressful; it is just so peaceful and that is like the time when I'm not bothered by anything. [41 YR WM]

Focusing on family provided motivation to cope with treatment burden. Patients cared about their loved ones and wanted to be around for them. 
I'm just trying to just live life one day at a time and be here longer for my kids [...]. [44 YR AAM]

Subtheme 3: Spirituality and faith

Spiritual or religious coping helped patients find meaning or gain comfort.

I look at the whole picture together with mind, body, and spirit. [...] So I do spend time in prayer and meditation, which also contributes to my well-being. [52 YR WF]

Me trying to please God is what's important to me. So I had to change my lifestyle and make healthy choices and better choices. [45 YR AAF]

\section{Theme 3: Questioning the notion of burden}

Some patients question the very notion of treatment burden as a result of a) adapting to one's situation or b) comparing oneself to others.

\section{Subtheme I: Adaptation/normalizing self-care}

Over time, some patients learned to efficiently manage all of their health care demands. To them, the self-care regimen was simply a "normal part of life" and not especially burdensome.

It's just things that I have to do, and I know I have to do them if I'm going to get well. There's really no problem about it. I just do it because I know that's what I'm supposed to do. [59 YR AA/NAF]

But none of this stuff that I have to do is [...]. I can't really say it is a burden. It is just something you learn to do. [74 YR WF]

\section{Subtheme 2: Social comparisons}

Comparing oneself to other people helped some patients convince themselves that their situation was not especially limiting and could be managed.

And there is even a guy who climbed Mt Everest with type 1 diabetes. So it is not like it keeps you from doing anything. [41 YR WM]

So I mean, my whole thing is just don't be a baby about it, suck it up, it could be way worse. It could be I currently have like really bad cancer right now or something. [...] a lot of other people have it worse. [26 YR WM]

\section{Theme 4: Receiving support from others}

Beyond the personal resources drawn on, patients also rely on family members, friends, and coworkers to provide informational, instrumental, emotional, and companionship support.

\section{Subtheme I: Informational support}

Some patients' family members or friends had personal experience with chronic conditions or work in the health care field, making them trusted sources of health-related information.

The person I go to the pool with, she is overweight too, so we talk about that. And I have a friend who lives in another town who has diabetes and, so, I kind of talk about it with him. [60 YR WF]

My daughter-in-law is an RN and she gives me advice on different things. [73 YR WF]

\section{Subtheme 2: Instrumental support}

Instrumental support (ie, task help) included help organizing medications, cooking healthy foods, and attending or tracking appointments. Some patients spoke about other people taking charge of their care, for example being responsible for knowing about appointments or medications.

All my grandkids know I take medication. They know how to push the button on the machine to get my medication out in case I can't do it myself. [59 YR AA/NAF]

And so [my wife] has all of my appointments and everything. [...] she's got all of her appointments, all of my appointments. [58 YR AAM]

Mayo Clinic patients were more likely to mention spouses as providers of this type of support, while HCMC patients more frequently spoke of Personal Care Assistants, siblings, children/grandchildren, and extended family members as providers of task help.

\section{Subtheme 3: Emotional and companionship support}

Emotional support may come in the form of a phone call or visit from a family member or friend. Some patients touched on the empathy provided by "fellow sufferers," while others noted the importance of having companions with whom they could share healthy activities.

But my sisters always call me, "Hey sis, you okay? You wanna talk? Do you need anything? Are you taking care of yourself?" [45 YR AAF]

I have three very good friends that understand the disease and know how to cope with it. One actually went through depression herself so she is able to talk to me on the same level. [46 YR WF] 
My husband and I walk together and bike together [...]. And in Arizona, there is a group of us that do different exercises and things. [61 YR WF]

\section{Theme 5: Positive aspects of health care}

Patients described elements of the health care system that seemed to reduce treatment burden (eg, care coordination and continuity) as well as constructive interactions with individual providers.

\section{Subtheme I: Systemic aspects}

Patients viewed a well-coordinated health care system favorably. Some noted the benefit of being embedded within a network of providers who communicate with one another about the care of patients.

This is a good hospital system because I have all of my doctors all in one network, so that makes it easier. [38 YR AAM]

They're all in the same clinic area, like teamwork. They all pretty much know what's going on with me before I even say anything. [44 YR NAF]

Patients in both settings stressed the importance of being in one health care system that manages all of their care needs.

\section{Subtheme 2: Individual-provider aspects}

Patients reported instances of good communication with a provider where they felt listened to and respected and their care was aligned with their needs. Particularly helpful was the provider who could explain things in ways that the patient could understand.

Always easy to talk to, she [the physician] knows exactly my history and so when I come in she knows exactly what I need, and we work together on what works and what doesn't for me. [54 YR WF]

Now the doctor I have now, she's more of a holistic doctor. She treats $[\ldots]$ "Well, how you feeling today? [...] are you sad today? Are you happy? How's your medicine making you feel?" You know, and I prefer a holistic approach. [45 YR AAF]

He takes time to explain to you what's going on with you. [...] like, when my sugar is up, he explains to me how my body may react to it. [59 YR AA/NAF]

When the provider-patient relationship was good, trust was high and patients were honest and more motivated to take care of themselves.
I think if you get a good doctor, someone that [has] known you for years, a little bit of your social life, I think he will take better care than $[\ldots]$ someone that you're not on good terms with, you hate to come see them when it's time to come visit them. And things that you should be telling, you're not telling because you and this doctor don't have a good relationship. [48 YR AAM]

I guess it is trust, it is a feeling of trust, and that is really important. But he [physician] has that confidence in me and I have definite confidence in him. [66 YR WF]

$[\ldots]$ it hit me going through the calls with the diabetes call line and then seeing [the doctor] that they [the health care providers] care about my health and they are trying the best they can to motivate me. And so I should respond to that and take care of myself. [60 YR WF]

\section{Focus group results}

FGs were used to confirm the themes that emerged from the interviews. As indicated in Table 2, all five of the major themes emerging from the interviews were also observed in the FGs. However, the FGs revealed two new subthemes within the problem-focused strategies theme: preserving autonomy/independence and being proactive with providers. These are described below and listed with representative quotes. Given that all of the major themes (five of five [100\%]) and most of the subthemes (14 of 16 [88\%]) were observed in both the interviews and FGs, content saturation was demonstrated.

\section{Additional problem-focused strategies} Subtheme 5: Preserving autonomy/independence Organization and planning provided structure for patients' self-care work and treatment, but FG participants also described a need to preserve autonomy and independence. They used language like "taking control of my body" to describe their role in managing their care. It was their job to take care of their health - not the responsibility of doctors or anyone else. Some patients exerted autonomy by teaching others.

It all goes back to paying attention to your body and being the captain of your own ship. If somebody tells you something, don't blindly do it. Make sure that you know. [HCMC FG \#1]

Medicine don't stop with the doctor. You have to kind of help it along. [HCMC FG \#1]

My health is better because I have people ask me about how to do things. [...] if you don't keep up on taking care 
of your [self], how can you tell somebody else how to deal with the situation? [Mayo Clinic FG \#1]

\section{Subtheme 6: Being proactive with providers}

Patients' proactive behavior sometimes extended to influencing relationships and communication with their health care providers. This included a range of activities related to provider-patient communication, with patients describing themselves as being advocates for good provider care.

And if I don't like what the doctor is telling me, and me and them ain't on the same boat, use your common sense. Get rid of them and get another one. [...] You got to be on the same page. [HCMC FG \#1]

I ask a lot of questions [...]. I keep asking questions until I get the answer I want [...]. I'm better at diagnosing myself than they are at times, it seems. [HCMC FG \#2]

I'm in total charge because at the end of the day, no matter what the doctors tell me, if I don't feel good about it, I've got a mouth; I'm going to tell him or her. It's as simple as that because it's a partnership. [HCMC FG \#1]

\section{Discussion}

The aim of this study was to identify factors that may lessen patients' perceptions of treatment burden. We found that patients with multiple and complex chronic conditions draw upon a range of personal, social, and health care resources to help them manage and cope with the demands of complex self-care. Some of these resources lie within a patient's control. For instance, patients reported using problem-focused strategies to make caring for themselves easier, such as creating self-care routines and using available technologies like online portals. Emotion-focused strategies, such as focusing on other life priorities and turning to spirituality and faith for comfort, could help to manage any negative emotions arising from the burdensome work of self-care. In addition to alleviating distress, coping strategies, like planning for the future, maintaining a positive attitude, focusing on other life priorities and spirituality and religious faith, can also bolster a sense of positive well-being, as evidenced by patient responses. This is consistent with the notion of "meaning-based coping" as defined in Folkman's theoretical model of stress and coping. ${ }^{26,27}$ Finally, patients also spoke of resources external to themselves, like support from social network members and access to a good health care system and providers with good interpersonal skills.

Our findings are consistent with those of other studies showing the importance of routinization (ie, making care a routine part of daily life) in shaping the perceptions of treatment burden, especially among patients who have managed their condition for a long time. ${ }^{10,14,17,19}$ Like us, other investigators have identified system- and provider-level health care factors, such as coordination of care and communication, that may influence a patient's experience of treatment burden. ${ }^{1,5,28}$ The role of factors such as learning about the condition and social support in alleviating perceived burden has been supported in several disease-specific studies. ${ }^{9,10,14,19,28}$ More broadly, there is considerable evidence in the chronic illness literature linking factors such as optimism, social support, and spirituality to greater psychological well-being, use of more adaptive forms of coping, and adherence to self-care regimens. ${ }^{29-31}$ Prior literature has also supported the utility of comparing oneself with others who are better and worse off as a means of adapting to threatening or stressful circumstances. ${ }^{32,33}$

Our study extends previous work by its application to patients with multimorbidity. In particular, these findings highlight the complex nature of interacting care plans among patients with multimorbidity, and the factors, including coordination of care, that may alleviate the confusion resulting from those interactions. The consistency of the themes observed across the interviews and FGs held with this diverse sample of patients suggests that there is some commonality to the coping strategies employed.

Our findings also question the notion that a simple count of the number or types of condition(s) is a sufficient measure of treatment burden, given that a patient's perception of burden is also informed by his or her ability to cope with it. A focus on the factors that may lessen or mitigate the treatment burden fits with several recent conceptualizations and theories that have been used to understand the construct. Shippee et $\mathrm{al}^{23}$ proposed a "cumulative complexity" model that posits that treatment burden is the result of imbalance between patient "workload" (ie, day-to-day demands and responsibilities) and patient "capacity" (ie, abilities, resources, or readiness to address demands). Patients with few demands but low capacity may experience burden whereas those with many demands but high capacity may not. Examples of patient capacity include health status (eg, physical/mental functioning and symptoms), financial status, literacy, social support, attitudes/beliefs, and personal characteristics (eg, self-efficacy). The conceptual framework derived in our study appears to illuminate elements of patient capacity, especially personal and social resources that a patient could draw upon to cope with and adapt to complex self-management. 
May's normalization process theory (NPT) has also been used as an analytic framework for understanding treatment burden. ${ }^{14,28}$ NPT explains the process by which a collection of novel practices is implemented, embedded, and integrated into a person's everyday life, vis-à-vis four basic mechanisms. ${ }^{34,35}$ Elements of at least three of these mechanisms are illustrated within our framework. "Sense-making work" and "enacting work" are inherent in the problem- and emotion-focused strategies patients reported using, such as routinizing selfcare, using technologies, preserving autonomy, and seeking spirituality and faith. "Relationship work" or engaging with others, both members of one's social network and health care providers, was largely represented in our themes 4 and 5 (receiving support from others and positive aspects of health care). Hence, our results fit with existing models and theories that have been used to understand treatment burden.

Our findings also fit with contemporary theories of stress and coping, especially Hobfoll's Conservation of Resources (COR) theory, a theory that has been applied to challenging work circumstances and burnout. ${ }^{36-38}$ Factors that may lessen treatment burden can be construed as "resources." In COR theory, resources are the single unit for understanding stress. ${ }^{36}$ Resources can be objects (eg, car or house), personal characteristics (eg, personal skills and traits, like self-efficacy and self-esteem), conditions (eg, employment, marriage, or seniority), energies (eg, time and knowledge), and social support. Resources are valued in and of themselves or as a means of acquiring other resources. The basic tenets of COR theory are that people strive to retain, protect, and build resources, in order to pursue things that they centrally value in life and that the potential or actual loss of these resources is threatening (ie, stressful). In our framework, personal characteristic resources were well-represented (ie, problem- and emotion-focused coping strategies, adaptation to self-care), as was social support (ie, receiving support from one's social network). Having such resources available could counteract the negative impact of the often excessive demands that modern health care places on people with multimorbidity. Maintaining personal resource reservoirs can promote resilience (ie, withstanding stressful challenges while also remaining committed and absorbed in important life tasks). ${ }^{37}$ Furthermore, we found that health care providers (both systems and practitioners) can play a key role in mitigating treatment burden by creating supportive environments that foster patient engagement and resilience, a concept referred to in COR theory as "caravan passageways." ${ }^{38}$ For example, an enriched health care environment, one in which care continuity is maintained and providers tailor care plans to the needs of each patient, may foster deeper engagement and even motivate patients to care for themselves. As one patient in our study remarked, "they [the health care providers] care about my health, and they are trying the best they can to motivate me. And so I should respond to that and take care of myself."

\section{Limitations}

Our study does have some limitations. First, while this qualitative study did help us to understand what factors patients believe are helpful at mitigating treatment burden, the true extent to which these factors actually do mitigate treatment burden will require further testing in larger studies, most likely involving surveys of operationalized constructs. Second, since there is no standard way to assess treatment burden, patients were identified by proxy, using factors believed to be consistent with the concept (eg, number of chronic conditions, number of medications, disease type), and these factors may have screened out patients with important information to share. Furthermore, these inclusion criteria were based on patient self-report and were not validated against information in the medical record, but we believe patients' recall of conditions may be a good reflection of what they perceive as the most salient conditions of their treatment work. Among those approached, it is possible that the most burdened patients declined to be interviewed due to barriers, including lack of available time or illness exacerbation. Finally, the qualitative nature of this study did not allow us to definitively test whether there were differences in types of resources by race/ethnicity or socioeconomic status. While our analysis did suggest a few differences in themes across the two research settings, it is difficult to ascertain which specific patient characteristics explain these differences without statistically controlling for other related factors that may act as confounders. We do believe that testing for such differences does warrant further examination as it may have implications for tailoring interventions to patients' available resources or shoring up resource deficiencies in different patient subgroups.

\section{Conclusion}

In attempting to understand treatment burden, it is equally important to understand the factors that may lessen it. Our study elucidates some of the personal, social, and health care provider factors that patients may rely on to mitigate perceived treatment burden. These factors outline a framework that could serve as a conceptual foundation for the development of a new patient self-report measure of capacity, 
one that would complement assessments of treatment burden. Indeed, a full accounting of a patient's treatment and selfcare situation is likely incomplete without assessments of both burden and capacity. ${ }^{23}$ From the clinician's standpoint, designing tools that help identify treatment burden as well as available self-management resources could foster more open, honest conversations between clinicians and patients about the unique challenges that patients face as they attempt to adhere to prescribed treatments and care. From the intervention standpoint, identifying patients who lack the appropriate access or ability to recruit resources to cope with their treatment burden may help identify those at risk for poor clinical outcome. Empirically testing resources to determine which best support the work of enacting specific treatment/ self-care demands might ultimately help tailor resource training or allocation to the needs of specific patients. ${ }^{36}$

\section{Acknowledgments}

The research reported in this publication was supported by the Sponsorship Research Board of St Marys Hospital (Rochester, MN); the Mayo Clinic Center for Translational Science Activities through grant number UL1 RR024150 from the National Center for Research Resources, a component of the National Institutes of Health; and the National Institute of Nursing Research of the National Institutes of Health under award number R21NR012984. DRdO, VMM, and DTE are part of the International Minimally Disruptive Medicine Workgroup. Workgroup members include Gene Beyt, Amy Bodde, Kasey Boehmer, Juan Pablo Brito, David Eton, Katie Gallacher, Michael Gionfriddo, Leona Han, AnneRose Kaiya, Maya Kessler, Aaron Leppin, Sara Macdonald, Frances Mair, Carl May, Victor Montori, Megan Morris, Djenane Oliveira, Nilay Shah, Nathan Shippee, Amit Sood, Robert Stroebel, Kristin Vickers Douglas, and Kathleen Yost.

\section{Disclosure}

The authors report no conflicts of interest in this work.

\section{References}

1. Eton DT, Ramalho de Oliveira D, Egginton JS, et al. Building a measurement framework of burden of treatment in complex patients with chronic conditions: a qualitative study. Patient Relat Outcome Meas. 2012;3:39-49.

2. Haynes RB, McDonald HP, Garg AX. Helping patients follow prescribed treatment: clinical applications. JAMA. 2002;288(22):2880-2883.

3. Vijan S, Hayward RA, Ronis DL, Hofer TP. Brief report: the burden of diabetes therapy: implications for the design of effective patient-centered treatment regimens. J Gen Intern Med. 2005;20(5):479-482.

4. Ho PM, Rumsfeld JS, Masoudi FA, et al. Effect of medication nonadherence on hospitalization and mortality among patients with diabetes mellitus. Arch Intern Med. 2006;166(17):1836-1841.
5. Rasmussen JN, Chong A, Alter DA. Relationship between adherence to evidence-based pharmacotherapy and long-term mortality after acute myocardial infarction. JAMA. 2007;297(2):177-186.

6. Brod M, Hammer M, Christensen T, Lessard S, Bushnell DM. Understanding and assessing the impact of treatment in diabetes: the Treatment-Related Impact Measures for Diabetes and Devices (TRIM-Diabetes and TRIM-Diabetes Device). Health Qual Life Outcomes. 2009;7:83.

7. Pifferi M, Bush A, Di Cicco M, et al. Health-related quality of life and unmet needs in patients with primary ciliary dyskinesia. Eur Respir J. 2010;35(4):787-794.

8. McGlynn EA, Asch SM, Adams J, et al. The quality of health care delivered to adults in the United States. N Engl J Med. 2003;348(26): 2635-2645.

9. Riegel B, Carlson B. Facilitators and barriers to heart failure self-care. Patient Educ Couns. 2002;46(4):287-295.

10. George M, Rand-Giovannetti D, Eakin MN, Borrelli B, Zettler M, Riekert KA. Perceptions of barriers and facilitators: self-management decisions by older adolescents and adults with CF. J Cyst Fibros. 2010;9(6):425-432.

11. Griva K, Ng HJ, Loei J, Mooppil N, McBain H, Newman SP. Managing treatment for end-stage renal disease - a qualitative study exploring cultural perspectives on facilitators and barriers to treatment adherence. Psychol Health. 2013;28(1):13-29.

12. Boyd CM, Fortin M. Future of multimorbidity research: How should understanding of multimorbidity inform health system design. Public Health Rev. 2010;32(2):451-474.

13. Feinstein AR. The pre-therapeutic classification of co-morbidity in chronic disease. J Chronic Dis. 1970;23(7):455-468.

14. Gallacher K, May CR, Montori VM, Mair FS. Understanding patients' experiences of treatment burden in chronic heart failure using normalization process theory. Ann Fam Med. 2011;9(3):235-243.

15. Bayliss EA, Steiner JF, Fernald DH, Crane LA, Main DS. Descriptions of barriers to self-care by persons with comorbid chronic diseases. Ann Fam Med. 2003;1(1):15-21.

16. May C, Montori VM, Mair FS. We need minimally disruptive medicine. BMJ. 2009;339:b2803.

17. Sav A, Kendall E, McMillan SS, et al. 'You say treatment, I say hard work': treatment burden among people with chronic illness and their carers in Australia. Health Soc Care Community. 2013;21(6):665-674.

18. Vogeli C, Shields AE, Lee TA, et al. Multiple chronic conditions: prevalence, health consequences, and implications for quality, care management, and costs. J Gen Intern Med. 2007;22 Suppl 3:S391-S395.

19. Sav A, King MA, Whitty JA, et al. Burden of treatment for chronic illness: a concept analysis and review of the literature. Health Expect. Epub January 31, 2013.

20. Zulman DM, Asch SM, Martins SB, Kerr EA, Hoffman BB, Goldstein MK. Quality of care for patients with multiple chronic conditions: the role of comorbidity interrelatedness. J Gen Intern Med. Epub October 1, 2013.

21. Valderas JM, Starfield B, Sibbald B, Salisbury C, Roland M. Defining comorbidity: implications for understanding health and health services. Ann Fam Med. 2009;7(4):357-363.

22. Boyd CM, Darer J, Boult C, Fried LP, Boult L, Wu AW. Clinical practice guidelines and quality of care for older patients with multiple comorbid diseases: implications for pay for performance. JAMA. 2005;294(6):716-724.

23. Shippee ND, Shah ND, May CR, Mair FS, Montori VM. Cumulative complexity: a functional, patient-centered model of patient complexity can improve research and practice. J Clin Epidemiol. 2012;65(10): 1041-1051.

24. Ritchie J, Lewis J, editors. Qualitative Research Practice: A Guide for Social Science Students and Researchers. London, UK: Sage; 2003.

25. Krueger RA, Casey MA. Focus Groups: A Practical Guide for Applied Research. 4th ed. Thousand Oaks, CA: SAGE; 2009.

26. Folkman S. Positive psychological states and coping with severe stress. Soc Sci Med. 1997;45(8):1207-1221. 
27. Folkman S, Greer S. Promoting psychological well-being in the face of serious illness: when theory, research and practice inform each other. Psychooncology. 2000;9(1):11-19.

28. Gallacher K, Morrison D, Jani B, et al. Uncovering treatment burden as a key concept for stroke care: a systematic review of qualitative research. PLoS Med. 2013;10(6):e1001473.

29. Park CL. Meaning, spirituality, and growth: Protective and resilience factors in health and illness. In: Baum A, Revenson A, Singer J, editors. Handbook of Health Psychology. 2nd ed. New York, NY: Psychology Press; 2012:405-430.

30. Scheier MF, Carver CS, Armstrong GH. Behavioral self-regulation, health, and illness. In: Baum A, Revenson A, Singer J, editors. Handbook of Health Psychology. 2nd ed. New York, NY: Psychology Press; 2012:79-98.

31. Wills TA, Ainette MC. Social networks and social support. In: Baum A, Revenson A, Singer J, editors. Handbook of Health Psychology. 2nd ed. New York, NY: Psychology Press; 2012:465-492.

32. Taylor SE, Lobel M. Social comparison activity under threat: downward evaluation and upward contacts. Psychol Rev. 1989;96(4):569-575.
33. Gerrard M, Gibbons FX, Reis-Bergan M, Trudeau L, Vande Lune LS, Buunk B. Inhibitory effects of drinker and nondrinker prototypes on adolescent alcohol consumption. Health Psychol. 2002;21(6): 601-609.

34. May CR, Mair F, Finch T, et al. Development of a theory of implementation and integration: Normalization Process Theory. Implement Sci. 2009;4:29.

35. Normalization process theory. NPT; 2010 [updated January 1, 2014; cited November 19, 2013]. Available from: http://www.normalizationprocess. org. Accessed December 1, 2013.

36. Hobfoll SE. Conservation of resources. A new attempt at conceptualizing stress. Am Psychol. 1989;44(3):513-524.

37. Hobfoll SE. Conservation of resources theory: its implications for stress, health, and resilience. In: Folkman S, editor. The Oxford Handbook of Stress, Health, and Coping. New York, NY: Oxford University Press; 2011:127-148.

38. Hobfoll SE. Conservation of resource caravans and engaged settings. J Occup Organ Psychol. 2011;84(1):116-122. 


\section{Supplementary material Additional patient quotes \\ Theme I: problem-focused strategies \\ Subtheme I: routinizing self-care}

And then, as far as remembering to take medications, the medications that I need to take in the morning, well, they're on that counter where I'm going to be, you know, next to the kitchen sink where I'm going to be. [Mayo Clinic FG \#1]

As long as you're structured, it's okay. Like Monday through Friday, I'm good; but Saturday and Sunday, it's [...] you know, you sleep a little later. You don't have the same structure, and it makes [...] makes for confusion. [Mayo Clinic FG \#1]

You get in a routine and you just kind of do it. It is just part of your day. [59 YR WF]

\section{Subtheme 3: planning for the future}

When we think about retirement and having health coverage, knowing that we are going to definitely need that because obviously the medications that I take will continue into my future, so we will need that. [54 YR WF]

\section{Subtheme 4: using technology}

If you've got a problem, send [the doctor] an email. [Mayo Clinic FG \#2]

I've got on my computer and my phone, I put reminders, sort of 'take your pills, dummy.' I mean, because there are times if I don't have that, I will forget. [Mayo Clinic $\mathrm{FG} \# 1$ ]

The cool thing now, with the [endocrinologist] that I have, we e-mail back and forth every week when there is something going on. Right now we are working with the insurance company trying to navigate everything through [...]. This morning I got on my Blackberry and sent him a message and he will pick it up on his Blackberry and then get back to me to figure out what the next steps are going to be. [41 YR WM]

\section{Subtheme 5: preserving autonomy/independence}

I don't need anybody to be concerned about me. As long as I worry about me, I'm fine. [HCMC FG \#2]

\section{Subtheme 6: being proactive with providers}

If I need to get a hold of the doctor about something that's going on in my body that we haven't discussed before, I can call his nurse $[\ldots]$ and they will eventually get to the doctor, and the doctor will get back to you. [Mayo Clinic FG \#2]

If you don't take charge and have one doctor, one doctor that controls all the doctors, you have a problem. [HCMC FG \#1]

I also think, sometimes, when you have to be your own advocate, sometimes, the doctor doesn't believe you or doesn't understand what you're going through. [Mayo Clinic FG \#1]

I used to not want to bother my doctor too much, or oh, we're going over time. Well, hey, it's about me [...] getting the optimal out of the health care situation to enhance my life. [Mayo Clinic FG \#1]

\section{Theme 2: emotion-focused coping}

Subtheme I: maintaining a positive attitude

Well no, but the thing is you've got to get to a positive place. If you stay negative or think so much, it becomes crazy making. [...] you're not gonna do the things you need to do to be healthy. [HCMC FG \#1]

I think if you don't have a sense of humor with some of these things that we all deal with, that'll kill you $[\ldots]$ you know, taking yourself too seriously. [HCMC FG \#1]

You know, maybe there are also good aspects of this. I was never a patient person. I've learned patience. [HCMC FG \#1]

\section{Subtheme 2: focusing on other life priorities}

I've got grandchildren that I love dearly and I have many good friends. I love my job. Those kinds of things keep me motivated. [60 YR WF]

\section{Theme 3: questioning the notion of burden}

Subtheme I: adaptation/normalizing self-care

It is a small percentage of my life that has been taken out by taking pills or going to the doctor. [...] that is not a major part [...] so I don't look at it as a dramatic burden. It is just something that I got to do. [36 YR AAM]

\section{Theme 4: receiving support from others}

Subtheme I: Informational support

[Wife] is a nurse at [clinic] so I just kind of ask her what she has seen. [...] she is pretty knowledgeable with what other people have taken. [...] she is pretty knowledgeable, yeah. [43 YR WM] 


\section{Subtheme 2: instrumental support}

My kids know I have it and they see me give shots, they see me test my blood sugar, they see me getting food to eat and they ask me if I am low or if I need something.

[41 YR WM]

\section{Subtheme 3: emotional and companionship support}

It really helps if I talk to other people that have experienced just being a heart patient [...] that really does help because sometimes you think 'Oh man, I'm the only one. I have to do this, this, and this, and I have to avoid this, this, and this'. [Mayo Clinic FG \#2]

Yah, both my wife and I probably have a need to lose weight so we support each other by trying to go for walks and get the kids to the park and keep the kids active. [43 YR WM]

That's the place [support group] I go where we get to be with people and they've got like the same illnesses like me. We understand one another, so that helps me out a lot. [38 YR AAM]

\section{Theme 5: positive aspects of health care}

\section{Subtheme I: systemic aspects}

It's a big circle they got. Everybody is in contact with everybody, and I'm the ball in the middle. [56 YR WM]
Most of the care is done with your primary physician, and if you have a good relationship with him, things just go real smooth. And if another doctor has to be involved, he gets [that] person involved and then you go see the person and they send the results back to [the primary physician]. [74 YR WF]

\section{Subtheme 2: individual-provider aspects}

[...] then he'll explain almost all details - this, that, and this is what's going to come out of it, and you know, just make sure you take your medication and that. And you don't mind hearing that, you know, as long as it's explained to you. What does it mean [...] if they explain it so you understand it more, then it's more relaxing. [61 YR WF]

And if they think that I need something and I don't want to have it, but they think I need it, then of course, I'll just go with it $[\ldots]$. But we come up to a conclusion together. [44 YR AAM]

You have some of those doctors that'll be like, 'Oh I'm a doctor, I know what I'm talking about,' and they really don't hear what you're saying. She hears what you're saying. [45 YR AAF]
Patient Preference and Adherence

\section{Publish your work in this journal}

Patient Preference and Adherence is an international, peer-reviewed, open access journal focusing on the growing importance of patient preference and adherence throughout the therapeutic continuum. Patient satisfaction, acceptability, quality of life, compliance, persistence and their role in developing new therapeutic modalities and compounds to

\section{Dovepress}

optimize clinical outcomes for existing disease states are major areas of interest. This journal has been accepted for indexing on PubMed Central. The manuscript management system is completely online and includes a very quick and fair peer-review system. Visit http://www.dovepress.com/ testimonials.php to read real quotes from published authors. 